\title{
Review
}

\section{Pharmacotherapy of COVID-19: Considerations for Pregnancy and Breastfeeding}

\author{
Amirreza Naseri 1,2, Sepideh Seyedi Sahebari 1, Mohammad-Salar Hosseini 1,3,4,*
}

1 Affiliation 1; Student Research Committee, Tabriz University of Medical Sciences, Tabriz, Iran
2 Affiliation 2; Aging Research Institute, Tabriz University of Medical Sciences, Tabriz, Iran
3 Affiliation 3; Emergency Medicine Research Team, Tabriz University of Medical Sciences, Tabriz, Iran
4 Affiliation 4; Research Center for Evidence-Based Medicine, Tabriz University of Medical Sciences, Tabriz,
Iran
* Correspondence: Research Center for Evidence-Based Medicine, Tabriz University of Medical Sciences, Gol-
gasht Street, Postal code 5166/15731, Tabriz, EA, Iran. hosseini.msalar@gmail.com; Tel.: +984133366581

Abstract: The coronavirus disease 2019 (COVID-19), caused by the severe acute respiratory syndrome coronavirus 2 (SARS-CoV-2) has become the chief concern of the international community in almost no time. As of May $9^{\text {th }}, 2021$, more than 150 million cases and 3.2 million deaths have been recorded. Considering the early struggle in treating COVID-19 patients, the researchers and clinicians have decided to try the previously available drugs according to their mechanisms of action. Hence, many antivirals, antibiotics, antiparasitics, and antipyretics have been proposed. Pregnant women, fetuses, and infants are known high-risk populations that are threatened during disease outbreaks. Therefore, this article reviews the safety of potential drugs for COVID-19 patients during pregnancy and breastfeeding.

Keywords: Angiotensin converting enzyme 2; breast feeding; drug therapy; pregnancy; severe acute respiratory syndrome coronavirus 2

\section{Introduction}

On January $7^{\text {th }}, 2020$, the Chinese Center for Disease Control and Prevention (China $\mathrm{CDC}$ ) identified a new coronavirus, later called the severe acute respiratory syndrome coronavirus 2 (SARS-CoV-2) by World Health Organization (WHO) [1]. The virus rapidly spread through the world and became a chief international concern, with more than 150 million confirmed cases and 3.2 million reported deaths till May 2021 [2]. From the first days, clinicians and researchers all over the world attempted to find effective drugs for the treatment of coronavirus disease 2019 (COVID-19), but no drug was approved as a definitive treatment, by WHO. In this situation, left with no other choice than using the formerly used drugs, most of the current clinical approaches consist of repurposing the previously available drugs which are expected to act as potential anti-COVID-19 agents, based on their underlying mechanisms of action.

Besides the general considerations regarding the drug-to-drug interactions, as the pregnant and the infants are among the most vulnerable groups, and the behavior of the virus among the pregnant women and infants is still ambiguous [3], we aim to review the safety of using the repurposed medications during the pregnancy and breastfeeding in this study. The proposed medications are as mentioned below:

\section{Antiparasitics}

Chloroquine and Hydroxychloroquine are FDA-approved agents against malaria. The immunomodulatory effects and the impact of inhibiting the virus-cell fusion have turned these drugs into prodigious hopes for COVID-19 treatment [4]. Although Chloroquine and Hydroxychloroquine can pass through the placental barrier, studies have 
shown that no danger threatens the fetus [5]. Despite the little excretion of Chloroquine into the milk, the American Academy of Pediatrics considers it compatible with breastfeeding, leaving no concern around the usage of Chloroquine and Hydroxychloroquine during the breastfeeding [6]. Recently, several studies, including the WHO Solidarity clinical trial, have reported that Chloroquine and Hydroxychloroquine have low efficacy in the treatment of COVID-19 patients, which has led to omitting these drugs from the COVID-19 treatment protocols in most of the countries [7].

\section{Antibiotics}

Azithromycin, as a broad-spectrum antibiotic in respiratory infections, is another drug that has been investigated as a choice of pharmacotherapy for SARS-CoV-2 infection. With a history of proven antiviral activity against Ebola, Zika, and Influenza A virus subtype H1N1, some researchers believe that comparing to Chloroquine and Hydroxychloroquine, Azithromycin could possibly be a better choice [8]. The results of studies have shown that the combination therapy of Hydroxychloroquine and Azithromycin was influential in the treatment of COVID-19 patients [9]. Nevertheless, a recent systematic review of the literature found no efficacy for this drug in COVID-19 patients [10]. Also, the results of COALITION I and II clinical trials in Brazil found no improvement in clinical outcomes of the 447 enrolled COVID-19 patients [11]. Today, the Infectious Diseases Society of America (IDSA) guideline recommends against the combination therapy of Azithromycin and Hydroxychloroquine because of reported increase in risk of QT prolongation, but this recommendation did not address the use of this drug against secondary bacterial pneumonia in COVID-19 patients [12]. Azithromycin excretes into human milk, but there are limited data available in both human and animal studies regarding the harmful effects of Azithromycin on the fetus or infant. However, in case of clear need, Azithromycin can be used during pregnancy and breastfeeding [13].

\section{Antivirals}

A failed Ebola drug, Remdesivir, acts well in shortening the recovery time of COVID19 patients. This drug was authorized by the FDA for emergency use on October $22^{\text {nd }}$, 2020. Although on November 20th, WHO recommended against Remdesivir [14], on November $25^{\text {th }}$, FDA declared that "The approval of Remdesivir for the treatment of patients hospitalized with COVID-19 met the legal and scientific standard" in a published statement [15]. The safety of Remdesivir usage during pregnancy and breastfeeding is still under investigation. However, its usage during pregnancy is only allowed after harm-benefit assessment for each patient. A case report of successful management of a pregnant woman in the third trimester with Remdesivir, recommended to include pregnant women in clinical trials [16]. Nevertheless, almost all clinical trials have excluded pregnant and breastfeeding women from their sample [17]. The results of a study conducted on pregnant women who were treated with Remdesivir, showed a high recovery rate with a low rate of serious adverse events [18]. In this study, 93\% of patients were recovered, and 90\% were discharged and the rate of serious adverse events was 16\%. Only the severe cases of COVID19 had the indication for Remdesivir injection. In this situation, it is most probable not to breastfeed their infants [19].

Lopinavir/Ritonavir as a licensed treatment for HIV had been recommended for COVID-19 treatment in many countries. Contrary to clinicians' hope, previous studies have shown no significant improvement in the clinical conditions of COVID-19 patients [7]. While the previous studies have shown no concern regarding the standard-dose prescription of this drug during pregnancy, the use of the oral solution is contraindicated during pregnancy, as it contains alcohol and propylene glycol [20]. Most of the available guidelines recommend HIV-infected mothers not to breastfeed their infants, so there is limited data about this drug's safety during breastfeeding. Despite the little excretion in breastmilk, there is no report of adverse events caused by using Lopinavir/Ritonavir in 
infants [21]. Also, low placental transfer of Lopinavir/Ritonavir has been reported in a recent systematic review [22].

Favipiravir is another potential antiviral agent against COVID-19. Even though there are reports of its efficacy against mild and moderate cases of COVID-19, there are numerous contrary studies available [23]. A recent systematic review has reported Favipiravir as an effective drug in improving the clinical condition of COVID-19 patients [24]. Although Favipiravir has received approval for emergency use in many countries, further studies are still needed to substantiate the effective role of this drug [25]. Thirty-one clinical trials have already been registered, which will provide more reliable evidence of using this drug against COVID-19. Favipiravir has shown teratogenic effects in several species and should not be prescribed for pregnant women [26]. There is no information about its excretion into milk and safety for the newborn [21], but according to animal studies, breastfeeding is contraindicated during the treatment course of Favipiravir [26].

Another proposed agent for COVID-19 therapy is Interferon beta-1a (IFb1a), an immunomodulatory agent with antiviral effects that is used in the treatment of multiple sclerosis (MS). Results of a clinical trial of 20 patients recommended adding IFb1a in the treatment regimen of infected patients [27]. Also, a controlled trial of safety and efficacy of inhaled nebulized Interferon beta-1a found it effective in treatment of COVID-19 [28], in contrast with the results of the WHO Solidarity study [29]. Notably, the pregnant and lactating women were excluded from the studies. Animal studies showed no teratogenic effects of IFbla. Even though the usage of this agent during pregnancy was contraindicated, on April $4^{\text {th }}, 2020$, FDA approved that the drug does not have deleterious effects on the pregnancy and pregnancy-related outcomes; however, most of the ongoing clinical trials excluded pregnant and lactating women from their study [30]. Since the levels of interferon beta-1a excretion in human milk are negligible, no adverse infant effects had been reported in women who have breastfed while taking IFb1a [19].

\section{Baricitinib}

Baricitinib is a long-term medication against rheumatoid arthritis, which has shown potential for COVID-19 treatment and received the FDA approval for emergency use, in combination with Remdesivir [31]. This approval was primarily based on the results of a large randomized controlled trial of 1033 participants, which showed that comparing with the Remdesivir mono-therapy, the combination of Remdesivir and Baricitinib has better efficacy in improving the clinical status of the COVID-19 patients [32]. Although a recent case report, stated the positive outcomes of using Baricitinib in the first 17 weeks of pregnancy [33], available clinical and experimental studies recommend against prescribing Baricitinib during pregnancy and breastfeeding.

\section{Antipyretics}

Fever is the most common symptom of COVID-19 [34]. Defects of craniofacial devolvement, teeth and heart problems are also commonly observed [35]. Even mild exposure during the preimplantation period could result in abortion [36]. In order to prevent the complications of fever, Acetaminophen is a safe choice for the pregnant, but the use of Ibuprofen is a point of controversy. Studies claim that Ibuprofen may exacerbate the patients' condition by increasing the amount of angiotensin-converting enzyme 2 (ACE2) [37]. On the other hand, there are studies claiming to treat critically ill patients by blocking the inflammatory mediator interleukin-6 with this drug [38]. Finally, on March 19th, the World Health Organization (WHO) stated that there is not enough evidence against the use of Ibuprofen, and they do not advise against it. Generally, pregnant women are recommended to avoid taking Ibuprofen, especially during the third trimester, since it could lead to premature closure of the fetal ductus arteriosus and develop heart problems in the fetus. Hence, physicians should weigh the benefits and harms before prescribing Ibuprofen. As a preferred choice of analgesic during lactation, the excretion of Ibuprofen into 
the breast milk is extremely low. It should be noted that NIH advises avoiding both Ibuprofen and Acetaminophen during the first trimester of the pregnancy.,

Table 1. Safety categories of potential COVID-19 drugs during pregnancy and excreted into milk.

\begin{tabular}{cccc}
\hline Drug & $\begin{array}{c}\text { Australian Drug pregnancy Cate- } \\
\text { gories }\end{array}$ & $\begin{array}{c}\text { United States FDA } \\
\text { pregnancy cate- } \\
\text { gory }\end{array}$ & $\begin{array}{c}\text { Excretion into hu- } \\
\text { man milk }\end{array}$ \\
\hline Acetaminophen & $\mathrm{A}$ & Not Assigned. & Yes \\
\hline Azithromycin & $\mathrm{B} 1$ & $\mathrm{~B}$ & Yes \\
\hline Baricitinib & $\mathrm{D}$ & $\begin{array}{c}\text { Not formally as- } \\
\text { signed. }\end{array}$ & Yes $^{2}$ \\
\hline Chloroquine & signed. & small amounts \\
\hline Favipiravir & $\mathrm{A} / \mathrm{D}^{1}$ & Not formally as- \\
signed. & - \\
\hline Hydroxychloroquine & - & C & small amounts \\
\hline Ibuprofen & $\mathrm{D}$ & C & - \\
\hline Interferon beta-1a & $\mathrm{C}$ & Not assigned. & Yes \\
\hline Lopinavir/Ritonavir & $\mathrm{D}$ & Not assigned. & Yes ${ }^{2}$ \\
\hline Remdesivir & $\mathrm{B} 3$ & $\mathrm{~B} 2$ &
\end{tabular}

${ }^{1}$ For malaria treatment: $\mathrm{D}$ and for Malaria prophylaxis: A.

${ }^{2}$ Based on animal studies.

\section{Conclusions}

Prescribing medication for pregnant or lactating patients infected with SARS-CoV-2 is challenging. A summary of drug safety for pregnancy and lactation is presented in Table 1 . The results of solidarity clinical trial for COVID-19 treatments launched by WHO found a little or no effect for Remdesivir, Hydroxychloroquine, Lopinavir and Interferon. More than mentioned drugs, novel ribonucleoside analog (NHC, EIDD-1931) was promising in recent studies. Preclinical studies found it a potential therapy against SARS-CoV2, MERS-CoV, and SARS-CoV, but we still need clinical studies to confirm its safety and efficacy. It seems that there is still a long way to find an effective drug for the treatment of COVID-19, therefore preventing from infection is the most effective way to cross through this pandemic.

Author Contributions: Conceptualization, A.N. and MS.H.; data curation, A.N. and S.S.; writingoriginal draft preparation, A.N. and S.S; writing - review and editing, MS.H.; project administration, MS.H. All authors have read and agreed to the published version of the manuscript.

Funding: This research received no external funding.

Institutional Review Board Statement: Not applicable.

Acknowledgments: None.

Conflicts of Interest: The authors declare no conflict of interest.

\section{References}

1. The Lancet. Emerging Understandings of 2019-nCoV. Lancet (London, England) 2020; 395 (10221): 311. [PMID: 31986259, DOI: 10.1016/S0140-6736(20)30186-0]

2. World Health Organization. WHO Coronavirus (COVID-19) Dashboard. https://covid19.who.int/ (accessed May 9th, 2021).

3. Oliveira LVd, Silva CRACd, Lopes LP, Agra IKR. Current evidence of SARS-CoV-2 vertical transmission: an integrative review. Revista da Associação Médica Brasileira 2020; 66: 130-5. [PMID: 32965371, DOI: 10.1590/1806-9282.66.s2.130]

4. Monteiro WM, Brito-Sousa JD, Baía-da-Silva D, Melo GC, Siqueira AM, Val F, Daniel-Ribeiro CT, Guimarães Lacerda MV. Driving forces for COVID-19 clinical trials using chloroquine: the need to choose the right research questions and outcomes. Revista da Sociedade Brasileira de Medicina Tropical 2020; 53. [PMID: 32267301, DOI: 10.1590/0037-8682-0155-2020] 
5. Rainsford K, Parke AL, Clifford-Rashotte M, Kean W. Therapy and pharmacological properties of hydroxychloroquine and chloroquine in treatment of systemic lupus erythematosus, rheumatoid arthritis and related diseases. Inflammopharmacology 2015; 23 (5): 231-69. [PMID: 26246395, DOI: 10.1007/s10787-015-0239-y]

6. Drugs Co. The transfer of drugs and other chemicals into human milk. Pediatrics 2001; 108 (3): 776-89. [PMID: 11533352, DOI: 10.1542/peds.108.3.776]

7. WHO Solidarity Trial Consortium, Pan H, Peto R, Henao-Restrepo AM, Preziosi MP, Sathiyamoorthy V, Abdool Karim Q, Alejandria MM, Hernández García C, Kieny MP, Malekzadeh R, Murthy S, Reddy KS, Roses Periago M, Abi Hanna P, Ader F, Al-Bader AM, Alhasawi A, Allum E, Alotaibi A, Alvarez-Moreno CA, Appadoo S, Asiri A, Aukrust P, Barratt-Due A, Bellani S, Branca M, Cappel-Porter HBC, Cerrato N, Chow TS, Como N, Eustace J, García PJ, Godbole S, Gotuzzo E, Griskevicius L, Hamra R, Hassan M, Hassany M, Hutton D, Irmansyah I, Jancoriene L, Kirwan J, Kumar S, Lennon P, Lopardo G, Lydon P, Magrini N, Maguire T, Manevska S, Manuel O, McGinty S, Medina MT, Mesa Rubio ML, Miranda-Montoya MC, Nel J, Nunes EP, Perola M, Portolés A, Rasmin MR, Raza A, Rees H, Reges PPS, Rogers CA, Salami K, Salvadori MI, Sinani N, Sterne JAC, Stevanovikj M, Tacconelli E, Tikkinen KAO, Trelle S, Zaid H, Røttingen JA, Swaminathan S. R epurposed Antiviral Drugs for Covid-19 Interim WHO Solidarity Trial Results. N Engl J Med. 384 (6): 497-511. [PMID: 33264556, DOI: 10.1056/NEJMoa2023184]

8. Bleyzac N, Goutelle S, Bourguignon L, Tod M. Azithromycin for COVID-19: More Than Just an Antimicrobial? Clin Drug Investig 2021; 40 (8): 683-686. [PMID: 32533455, DOI: 1 0.1007/s40261-020-00933-3]

9. Gautret P, Lagier JC, Parola P, Hoang VT, Meddeb L, Mailhe M, Doudier B, Courjon J, Giordanengo V, Vieira VE, Tissot Dupont H, Honoré S, Colson P, Chabrière E, La Scola B, Rolain JM, Brouqui P, Raoult D. Hydroxychloroquine and azithromycin as a treatment of COVID-19: results of an open-label non-randomized clinical trial. Int J Antimicrob Agents. $2020 ; 56$ (1): 105949. [PMID: 32205204, DOI: 10.1016/j.ijantimicag.2020.105949]

10. Abubakar AR, Sani IH, Godman B, Kumar S, Islam S, Jahan I, Haque M. Systematic Review on the Therapeutic Options for COVID-19: Clinical Evidence of Drug Efficacy and Implications. Infect Drug Resist 2020; 13: 4673-4695. [PMID: 33402839, DOI: 10.2147/IDR.S289037]

11. Furtado RHM, Berwanger O, Fonseca HA, Corrêa TD, Ferraz LR, Lapa MG, Zampieri FG, Veiga VC, Azevedo LCP, Rosa RG, Lopes RD, Avezum A, Manoel ALO, Piza FMT, Martins PA, Lisboa TC, Pereira AJ, Olivato GB, Dantas VCS, Milan EP, Gebara OCE, Amazonas RB, Oliveira MB, Soares RVP, Moia DDF, Piano LPA, Castilho K, Momesso RGRAP, Schettino GPP, Rizzo LV, Neto AS, Machado FR, Cavalcanti AB; COALITION COVID-19 Brazil II Investigators. Azithromycin in addition to standard of care versus standard of care alone in the treatment of patients admitted to the hospital with severe COVID-19 in Brazil (COALITION II): a randomised clinical trial. Lancet. 2020; 396 (10256): 959-967. [PMID: 32896292, DOI: 10.1016/S0140-6736(20)318626]

12. Bhimraj A, Morgan RL, Shumaker AH, Lavergne V, Baden L, Cheng VC, Edwards KM, Gandhi R, Muller WJ, O'Horo JC, Shoham S, Murad MH, Mustafa RA, Sultan S, Falck-Ytter Y. Infectious Diseases Society of America Guidelines on the Treatment and Management of Patients with COVID-19. Clin Infect Dis. 2020: ciaa478. [PMID: 32338708, DOI: 10.1093/cid/ciaa478]

13. Keskin-Arslan E, Kaplan YC, Koren G. Use of azithromycin during pregnancy and breastfeeding: A coronavirus pan-demic (COVID-19) update. Motherisk Int J 2020; 1 (12).

14. World Health Organization. WHO recommends against the use of remdesivir in COVID-19 patients. https://www.who.int/news-room/feature-stories/detail/who-recommends-against-the-use-of-remdesivir-in-covid-19-patients/ (accessed March 16th, 2021).

15. U.S. Food \& Drug Administration. Remdesivir (Veklury) Approval for the Treatment of COVID-19-The Evidence for Safety and Efficacy. https://www.fda.gov/drugs/news-events-human-drugs/remdesivir-veklury-approval-treatment-covid-19-evidence-safety-and-efficacy (accessed March 16th, 2021).

16. Maldarelli GA, Savage M, Mazur S, Oxford-Horrey C, Salvatore M, Marks KM. Remdesivir Treatment for Severe COVID-19 in Third-Trimester Pregnancy: Case Report and Management Discussion. Open Forum Infect Dis. 2020; 7 (9): ofaa345. [PMID: 32934969, DOI: 10.1093/ofid/ofaa345]

17. Berghella V, Hughes B. Coronavirus disease 2019 (COVID-19): Pregnancy issues and antenatal care. UpToDate. https://www.uptodate.com/contents/covid-19-pregnancy-issues-and-antenatal-care. (accessed March 16th, 2021)

18. Burwick RM, Yawetz S, Stephenson KE, Collier AY, Sen P, Blackburn BG, Kojic EM, Hirshberg A, Suarez JF, Sobieszczyk ME, Marks KM, Mazur S, Big C, Manuel O, Morlin G, Rose SJ, Naqvi M, Goldfarb IT, DeZure A, Telep L, Tan SK, Zhao Y, Hahambis T, Hindman J, Chokkalingam AP, Carter C, Das M, Osinusi AO, Brainard DM, Varughese TA, Kovalenko O, Sims MD, Desai S, Swamy G, Sheffield JS, Zash R, Short WR. Compassionate Use of Remdesivir in Pregnant Women with Severe Covid-19. Clin Infect Dis. 2020: ciaa1466. [PMID: 33031500, DOI: 10.1093/cid/ciaa1466]

19. Anderson PO. Antivirals for COVID-19 and Breastfeeding. Breastfeed Med. 2020; 15 (10): 605-607. [PMID: 32936682, DOI: 10.1089/bfm.2020.0268]

20. Pasley MV, Martinez M, Hermes A, d'Amico R, Nilius A. Safety and efficacy of lopinavir/ritonavir during pregnancy: a systematic review. AIDS Rev 2013; 15 (1): 38-48. [PMID: 23449228.]

21. Levonorgestrel Implant. Drugs and Lactation Database (LactMed)[Internet]. Bethesda (MD): National Library of Medicine (US) 2019: 63-67.

22. Louchet M, Sibiude J, Peytavin G, Picone O, Tréluyer JM, Mandelbrot L. Placental transfer and safety in pregnancy of medications under investigation to treat coronavirus disease 2019. Am J Obstet Gynecol MFM. 2020; 2 (3): 100159. [PMID: 32838264, DOI: 10.1016/j.ajogmf.2020.100159] 
23. Chen C, Huang J, Cheng Z, et al. Favipiravir versus arbidol for COVID-19: a randomized clinical trial. MedRxiv 2020. [DOI: 10.1101/2020.03.17.20037432]

24. Wei FF, Moradkhani A, Hemmati Hezaveh H, Miraboutalebi SA, Salehi L. Evaluating the Treatment with Favipiravir in Patients Infected by COVID-19: A Systematic Review and Meta-analysis. International Journal of Scientific Research in Dental and Medical Sciences 2020; 2(3): 87-91. [DOI: 10.30485/IJSRDMS.2020.241494.1079]

25. Agrawal U, Raju R, Udwadia ZF. Favipiravir: A new and emerging antiviral option in COVID-19. Med J Armed Forces India. 2020; 76 (4): 370-376. [PMID: 32895599, DOI: 10.1016/j.mjafi.2020.08.004]

26. Hayden FG, Shindo N. Influenza virus polymerase inhibitors in clinical development. Curr Opin Infect Dis. 2019 ; 32 (2): 176186. [PMID: 30724789, DOI: 10.1097/QCO.0000000000000532]

27. Payandemehr P, Azhdarzadeh M, Bahrami-Motlagh H, et al. Interferon beta-1a as a Candidate for COVID-19 Treatment; An Open-Label Single-Arm Clinical Trial. Advanced Journal of Emergency Medicine 2020; 4 (2s): e51-e. [DOI: 10.22114/ajem.v4i2s.454]

28. Monk PD, Marsden RJ, Tear VJ, Brookes J, Batten TN, Mankowski M, Gabbay FJ, Davies DE, Holgate ST, Ho LP, Clark T, Djukanovic R, Wilkinson TMA; Inhaled Interferon Beta COVID-19 Study Group. Safety and efficacy of inhaled nebulised interferon beta-1a (SNG001) for treatment of SARS-CoV-2 infection: a randomised, double-blind, placebo-controlled, phase 2 trial. Lancet Respir Med. 2021; 9 (2): 196-206. [PMID: 33189161, DOI: 10.1016/S2213-2600(20)30511-7]

29. Peiffer-Smadja N, Yazdanpanah Y. Nebulised interferon beta-1a for patients with COVID-19. Lancet Respir Med. 2021; 9 (2): 122-123. [PMID: 33189160, DOI: 10.1016/S2213-2600(20)30523-3]

30. Bosi E, Bosi C, Rovere Querini P, Mancini N, Calori G, Ruggeri A, Canzonieri C, Callegaro L, Clementi M, De Cobelli F, Filippi $\mathrm{M}$, Bregni M. Interferon $\beta$-1a (IFN $\beta$-1a) in COVID-19 patients (INTERCOP): study protocol for a randomized controlled trial. Trials. 2020 Nov; 21 (1): 939. [PMID: 33225960, DOI: 10.1186/s13063-020-04864-4]

31. U.S. Food \& Drug Administration. Coronavirus (COVID-19) Update: FDA Authorizes Drug Combination for Treatment of COVID-19. 2020. https://www.fda.gov/news-events/press-announcements/coronavirus-covid-19-update-fda-authorizes-drugcombination-treatment-covid-19. (accessed March 16th, 2021).

32. Kalil AC, Patterson TF, Mehta AK, Tomashek KM, Wolfe CR, Ghazaryan V, Marconi VC, Ruiz-Palacios GM, Hsieh L, Kline S, Tapson V, Iovine NM, Jain MK, Sweeney DA, El Sahly HM, Branche AR, Regalado Pineda J, Lye DC, Sandkovsky U, Luetkemeyer AF, Cohen SH, Finberg RW, Jackson PEH, Taiwo B, Paules CI, Arguinchona H, Erdmann N, Ahuja N, Frank M, Oh MD, Kim ES, Tan SY, Mularski RA, Nielsen H, Ponce PO, Taylor BS, Larson L, Rouphael NG, Saklawi Y, Cantos VD, Ko ER, Engemann JJ, Amin AN, Watanabe M, Billings J, Elie MC, Davey RT, Burgess TH, Ferreira J, Green M, Makowski M, Cardoso A, de Bono S, Bonnett T, Proschan M, Deye GA, Dempsey W, Nayak SU, Dodd LE, Beigel JH; ACTT-2 Study Group Members. Baricitinib plus Remdesivir for Hospitalized Adults with Covid-19. N Engl J Med. 2021; 384 (9): 795-807. [PMID: 33306283, DOI: 10.1056/NEJMoa2031994]

33. Costanzo G, Firinu D, Losa F, Deidda M, Barca MP, Del Giacco S. Baricitinib exposure during pregnancy in rheumatoid arthritis. Ther Adv Musculoskelet Dis. 2020; 12: 1759720X19899296. [PMID: 32071617, DOI: 10.1177/1759720X19899296]

34. Wang D, Hu B, Hu C, Zhu F, Liu X, Zhang J, Wang B, Xiang H, Cheng Z, Xiong Y, Zhao Y, Li Y, Wang X, Peng Z. Clinical Characteristics of 138 Hospitalized Patients With 2019 Novel Coronavirus-Infected Pneumonia in Wuhan, China. JAMA. 2020; 323 (11): 1061-1069. [PMID: 32031570, DOI: 10.1001/jama.2020.1585]

35. Le Gouez A, Benachi A, Mercier FJ. Fever and pregnancy. Anaesth Crit Care Pain Med. 2016; 35 Suppl 1:S5-S12. [PMID: 27386764, DOI: 10.1016/j.accpm.2016.06.007]

36. Edwards MJ. Review: Hyperthermia and fever during pregnancy. Birth Defects Res A Clin Mol Teratol. 2006; 76 (7): 507-16. [PMID: 16933304, DOI: 10.1002/bdra.20277]

37. Fang L, Karakiulakis G, Roth M. Are patients with hypertension and diabetes mellitus at increased risk for COVID-19 infection? Lancet Respir Med. 2020; 8 (4): e21. [PMID: 32171062, DOI: 10.1016/S2213-2600(20)30116-8]

38. Day M. Covid-19: ibuprofen should not be used for managing symptoms, say doctors and scientists. BMJ. 2020 ; 368 : m1086. [PMID: 32184201, DOI: 10.1136/bmj.m1086] 